\title{
CONTÁGORA: UMA EXPERIÊNCIA DIGITAL NA GESTÃO DE PEQUENOS E MÉDIOS NEGÓCIOS
}

\section{CONTÁGORA: A DIGITAL EXPERIENCE IN THE MANAGEMENT OF SMALL AND MEDIUM BUSINESSES}

\section{Jonathan Pio Borel Reis Friede ${ }^{\star \star}$ Maria Geralda de Miranda ${ }^{* \star \star}$}

Resumo: O uso de tecnologias mais eficientes e modernas tem se tornado cada vez mais evidente no mundo contemporâneo. A internet tem permitido que conhecimentos e tecnologias cheguem em áreas distantes dos grandes centros urbanos. Com isso o processo de globalização tem chegado em localidades interioranas e tem inserido as pessoas no mundo digital, o que permite crescimento econômico e desenvolvimento local. O presente estudo buscou refletir acerca da criação da startup Contágora, empresa de contabilidade digital, localizada na cidade de Manhuaçu, situada na Zona da Mata, no estado de Minas Gerais. Como resultado da observação ficou evidente que a empresa pode propiciar melhorias nos processos contábeis, facilitar a rotina do cliente e contribuir de maneira mais efetiva com a gestão, principalmente de pequenos e médios empreendimentos, além de contribuir com processos produtivos mais sustentáveis, porque em suas práticas de gestão e contabilidade elimina-se o uso de papel.

Palavras-chave: Contabilidade Digital. Internet.

Abstract: The use of more efficient and modern technologies has become increasingly evident in the contemporary world. The internet has allowed knowledge and technologies to reach areas far from large urban centers. With this, the globalization process has reached rural areas and has inserted people into the digital world, which allows for economic growth and local development. The present study sought to reflect on the creation of the startup Contágora, a digital accounting company, located in the city of Manhuaçu, located in Zona da Mata, in the state of Minas Gerais. As a result of the observation, it became evident that Contágora can provide improvements in the accounting processes, facilitate the client's routine and contribute more effectively to the management, mainly of small and medium enterprises, in addition to contributing to more sustainable production processes, because in its practices management and accounting eliminates the use of paper.

\footnotetext{
* Mestrado em Desenvolvimento Local pelo Centro Universitário Augusto Motta, (UNISUAM), Brasil. Professor do Centro Superior de Estudos de Manhuaçu, (UNIFACIG), Brasil. E-mail: jonathanborel@outlook.com.

** Desembargador Federal. Doutor em Direito pela Universidade Federal do Rio de Janeiro (UFRJ). Mestre em Direito pela Universidade Gama Filho (UGF). Professor e Pesquisador do Programa de Mestrado em Desenvolvimento Local do Centro Universitário Augusto Motta (UNISUAM). E-mail: reisfriede@hotmail.com.

*** Pós-doutora em políticas públicas pela Universidade do Estado do Rio de Janeiro (UERJ). Pesquisadora do Programa de Pós-Graduação em Desenvolvimento Local do Centro Universitário Augusto Motta (UNISUAM). E-mail: mgeraldamiranda@gmail.com.
} 
Keywords: Digital Accounting. Internet.

Recebido em: 29/04/2021. Aceito em: 30/04/2021. 


\section{INTRODUÇÃO}

O crescimento do uso da tecnologia, segundo o site Computer World (MERCADO, 2019) cresceu cerca de $118 \%$ em dez anos no Brasil, e que o setor de tecnologia é o que mais cresceu nos últimos anos, basta olhar para as marcas mais valiosas do mundo, Apple, Google, Amazon e Microsoft, ambas do setor de tecnologia e comércio.

Esse "movimento tecnológico", digamos assim, demonstra que o setor tem muito a crescer, pois o uso da tecnologia permite ultrapassar limites que antes não eram possíveis, o que tem impulsionado a globalização, apesar dos grandes abismos sociais que também nos últimos dez anos, paradoxalmente, se ampliaram no mundo.

A Internet das Coisas, conforme Santos (2016) se refere a uma extensão da Internet atual, que proporciona aos objetos do dia a dia capacidade computacional maior de controle remoto e de serviços, o que demonstra como os processos têm evoluído com a o uso da internet.

A Organização das Nações Unidas (ONU, 2020), em 2015 estabeleceu a Agenda 2030, que instituiu 17 Objetivos visando ao Desenvolvimento Sustentável (ODS). Nos dizeres da ONU trata-se de um "apelo global à ação para acabar com a pobreza, proteger o meio ambiente e garantir que as pessoas, em todos os lugares, possam desfrutar de paz e de prosperidade". O ODS 8 tem como foco a promoção do crescimento econômico inclusivo e sustentável. Objetivo tão importante que para ser atingido é preciso que os Estados, por meio de políticas públicas, proporcionem acesso à internet a todos. Também o ODS 12, que prevê adoção de padrões de produção e de consumo sustentáveis, só será possível com o uso da tecnologia na contabilidade, para que empreendedores possam utilizar documentos recebidos para efetuarem análise e pagamentos, sem precisar de impressão.

A necessidade de preservação do Planeta exige também a necessidade de inovação no âmbito de tecnologias limpas. É neste contexto que se criou a startup Contágora, que consiste num processo de mudanças no uso da tecnologia em contabilidade, com benefícios para toda a sociedade. E é neste contexto também que se insere o presente estudo, que buscou analisar o processo de criação de tal startup. 


\section{CONTABILIDADE: HISTÓRICO E IMPORTÂNCIA}

As primeiras informações sobre as atividades comerciais datam de 4.500 a.C., na Mesopotâmia, quando houve uma maior dedicação à agricultura e as relações culturais. Os registros da época, feito, em placas de argila, apresentavam os resultados das trocas de objetos feitas e dos impostos e taxas cobrados pelas entidades religiosas (PALHARES; RODRIGUES, 1990).

Segundo Agostini e Carvalho (2012) é possível identificar como diversas práticas contábeis feitas na época de forma rudimentares, faziam parte da cultura, com intuito apenas de controlar riquezas diversas. Mas a Contabilidade somente foi reconhecida como ciência durante o século XIX, tendo seu nome originado do termo contabilitá, proveniente da escola italiana, que significa registro de contas.

$\mathrm{Na}$ bíblia é possível identificar passagens, conforme afirmam ludícibus e Marion (2007) que citam que no livro de Jó, talvez o mais antigo, encontra-se um trecho que claramente evidencia a quantidade de animais possuídos por Jó, e que acaba perdendo tudo, mas consegue recuperá-los, tendo o dobro do que havia antes, o que demonstra uma situação de lucratividade.

ludícibus e Marion (2007) ressaltam que a história dos números se inicia com a obra Líber Abaci (Livro do ábaco), escrita em 1202, por Leonardo Pisano1, quando se introduz algarismos arábicos que eles haviam aprendido com hindus, aplicando esses conceitos a cálculos comerciais. Mas é em 1494, com Frei Lucas Pacioli, que a grande evolução acontece, pois consolida-se a partir de então a atual sistemática contábil das partidas dobradas, expressando a relação de causa e efeito do fenômeno patrimonial de débito e crédito.

Para Franco (1997, p. 21), a Contabilidade é a ciência que estuda os fenômenos ocorridos no patrimônio das entidades, mediante o registro, a classificação, a demonstração expositiva, análise e a interpretação desses fatos, com o fim de oferecer informações e orientação, necessárias à tomada de decisões - sobre a composição do patrimônio, suas variações e o resultado econômico decorrente da gestão da riqueza patrimonial. Assim, a contabilidade tem ganhado

1 Leonardo Pisano ou Fibonaci: Inglês Leonardo de Pisa, nome original de Leonardo Fibonacci (1170 - 1240), matemático italiano medieval, dito como o primeiro grande matemático europeu. Ficou conhecido pela descoberta da sequência de Fibonacci e pelo seu papel na introdução dos algarismos árabes na Europa (FIBONNACI, 2011). 
cada vez mais evidencia e importância no mundo e tem evoluído desde então. $\mathrm{O}$ quadro abaixo mostra a evolução da contabilidade:

Quadro 1 - Evolução da contabilidade.

\begin{tabular}{|l|l|}
\hline \multicolumn{1}{|c|}{ Período } & \multicolumn{1}{|c|}{ Características } \\
\hline Contabilidade do & $\begin{array}{l}\text { Período que se inicia com a civilização do homem e vai até 1202 da Era } \\
\text { Mundo Antigo quando apareceu o Líber Abaci, da autoria Leonardo Fibonaci, o } \\
\text { Pisano. }\end{array}$ \\
\hline $\begin{array}{l}\text { Contabilidade do } \\
\text { Mundo Medieval }\end{array}$ & $\begin{array}{l}\text { Período que vai de 1202 da Era Cristã até 1494, quando apareceu o } \\
\text { Tratactus de Computis et Seriptures (Contabilidade por Partidas } \\
\text { Dobradas) de Frei Luca Pacioli, publicado em 1494; enfatizando que à } \\
\text { teoria contábil do débito e do crédito corresponde à teoria dos números } \\
\text { positivos e negativos, obra que contribui para inserir a contabilidade } \\
\text { entre os ramos do conhecimento humano. }\end{array}$ \\
\hline Contabilidade do & $\begin{array}{l}\text { Período que vai de 1494 até 1840, com o aparecimento da Obra "La } \\
\text { Contabilità Applicatta Alle Amninistrazioni Private e Pubbliche", da } \\
\text { autora de Francesco Villa, premiada pelo governo da Áustria. Obra } \\
\text { marcante na história da Contabilidade. }\end{array}$ \\
\hline Contabilidade do Moderno & Período que se inicia em 1840 e continua até os dias de hoje. \\
Mundo Científico & \\
\hline
\end{tabular}

Fonte: Lima (2006, p. 1).

Bielinski (2000) pontuam que no Brasil, a Contabilidade, como campo de estudo, está intimamente ligada as necessidades dos comerciantes em aprimorar o controle de seus bens. No período colonial, cada comerciante fazia como podia e sabia, mas coma chegada da família real, em 1807, o comercio cresceu e exigiu profissionalismo. A profissão de contabilidade passou a adotar inúmeros nomes, entre ele o guarda-livros:

No ano de 1869 foi criado a Associação dos Guarda-Livros da Corte, sendo reconhecido oficialmente no ano seguinte pelo Decreto Imperial no 4.475 , este fato foi importante, pois estava constituído o guarda-livros, como a primeira profissão liberal do Brasil. O guarda-livros, como era conhecido antigamente 0 profissional de Contabilidade, era um profissional ou empregado incumbido de fazer os seguintes trabalhos da firma: elaborar contratos e distrato, controlar a entrada e saída de dinheiro, através de pagamentos e recebimentos, criar correspondências e fazer toda a escrituração mercantil. Exigia-se que estes profissionais tivessem domínio das línguas portuguesa e francesa, além de uma aperfeiçoada caligrafia. (REIS; SILVA, 2007, p. 4).

Mas com o tempo os diversos nomes dados para se referir à atividade foram evoluindo e ganhando cada vez mais notoriedade, principalmente quando as companhias abertas passam a ser obrigadas a padronizar suas demonstrações contábeis e a ser auditadas por auditores externos, isto tudo, com a influência norteamericana que se deu início com a promulgação da Lei 6.404/76 (NIYAMA, 2009). 
Com a criação dos Conselhos Regionais através do Decreto Lei 9.295, de 27 de maio de 1946, ficou mais claro o perfil dos profissionais de contabilidade, onde o primeiro a obter o registro no conselho foi o senador João Lyra, considerado patrono da classe contábil. A partir de 1981, o Conselho Federal de Contabilidade, estabeleceu Normas Brasileiras de Contabilidade NBC, o que deu ainda mais ênfase à profissão contábil, o que mostra que a contabilidade permanece em constante evolução, se adequando às necessidades atuais do mercado e de seus clientes.

O governo federal implantou o Sistema Público de Escrituração Digital, SPED, que consiste, conforme Sebold et al. (2012) na modernização da sistemática atual do cumprimento das obrigações acessórias, transmitidas pelos contribuintes às administrações tributárias e aos órgãos fiscalizadores, utilizando-se da certificação digital para fins de assinatura dos documentos eletrônicos, garantido assim a validade jurídica dos mesmos na sua forma digital.

O SPED faz parte do Programa de Aceleração do Crescimento, PAC, instituído pela Lei ${ }^{\circ} 6.022 / 07$ e diversas foram as evoluções que permite hoje discutir o assunto com mais clareza e comprometimento.

É por meio destas transformações trazidas pelo SPED que a contabilidade tem evoluído para um processo de contabilidade digital, porém muito profissionais e clientes não tem aderido por questões de segurança, pelo fato de terem contato com o profissional contratado, o que é algo negativo para seu processo de tomada de decisão. É neste contexto que entra a contabilidade na sua função gerencial e é neste âmbito que se situa a Contágora.

E assim enfatiza-se a necessidade do setor contábil brasileiro fazer uso da tecnologia a seu favor, uma vez que desde a década de 1980 tem-se acesso a microcomputadores e tem crescido a cada dia o número de softwares ligados à área de gestão, de administração, de contabilidade e área financeira, sendo a contabilidade, hoje, já realizada por meio de processos cada vez mais informatizados, com escrituração feita de forma eletrônica.

\section{METODOLOGIA}

O presente estudo se deu através da observação e pesquisa de ferramentas para caracterização do modelo de negócios, a partir do qual se criou a Contágora, 
empresa de Contabilidade digital.

Na primeira parte do trabalho foi adotada a pesquisa de revisão bibliográfica afim de entender como a contabilidade tem evoluído no passar dos tempos, e foi interessante observar que com o passar dos anos, muita coisa tem acontecido e algumas de maneira imperceptível sendo que uma delas é a intensificação dos processos de fiscalização com o uso da tecnologia.

Em seguida foi necessário observar os processos de funcionamento de um escritório de contabilidade tradicional, desde o atendimento ao cliente até a entrega de impostos e demonstrativos contábeis. Neste passo foi necessário observar por tempo integral todos os departamentos afins de compreender seus funcionamentos e da possibilidade de se implantar melhorias.

A fim de atender aos objetivos da pesquisa em criar um modelo de negócio no formato de startup, buscou-se identificar todos os problemas detectados no atendimento ao cliente no escritório tradicional até o serviço de marketing.

Para pesquisa de melhorias, o pesquisador participou de vários congressos e seminários contábeis associadas à tecnologia, com destaque para ContaAzul CON, Congresso Realizado no Estado de São Paulo em 2019, que tinha como foco principal a Contabilidade Digital e seu futuro, além disso foram feitas várias pesquisas na internet utilizando descritores, como: "contabilidade digital", "sistemas de gestão financeira e contábil integrados à contabilidade", "marketing digital", entre outros, afim de encontrar ferramentas de atendimento, gestão do escritório, gestão do cliente e marketing contábil.

O período de observação das atividades do escritório de contabilidade iniciou-se em abril de 2020, porém devido a pandemia do coronavírus foi necessário paralisar e retornar agora em agosto de 2020. Neste período de 4 meses foram observadas várias atividades do escritório, conforme descrição a seguir.

O escritório de contabilidade utilizado para o estudo está localizado na cidade de Manhuaçu, estado de Minas Gerais. A escolha foi em razão dele atender a cidade de Manhuaçu e regiões adjacentes.

\section{RESULTADOS E DISCUSSÃO}

$\mathrm{Na}$ atualidade, quando um empreendedor tem uma grande ideia, ele utiliza a 
internet para buscar por informações importantes acerca do negócio, procura saber quais são os primeiros passos, o que deve ser observado antes de começar, e muitas outras dúvidas que surgem no momento da pesquisa. Mas se em vez do empreendedor perder este tempo buscando respostas, se ele tiver à sua disposição, na internet, um serviço de contabilidade digital, que além de consultoria pode ajudálo a elaborar o seu plano de negócio, certamente aumentará suas chances de sucesso.

É exatamente neste momento que é necessário observar os processos de inovação que ocorrem na contabilidade, como já acontece na esfera governamental, onde os processos estão sendo cada vez mais digitais. Todavia, percebe-se que em municípios menores, como o de Manhuaçu, localizado na Zona da Mata mineira, com noventa mil habitantes, as inovações também têm chegado, de modo que a elaboração e criação de uma startup no âmbito da contabilidade digital pode contribuir com o desenvolvimento da região.

O consumo de materiais, entre eles o papel, em escritórios tradicionais, é muito grande. Com a implantação de escritório digital a economia é muito grande, porque elimina-se a impressão de papéis, a locomoção de sócios e colaboradores, além dos processos aconteceram mais rápido e de maneira mais eficazes, além de estar em sintonia com os Objetivos do Desenvolvimento Sustentável da ONU.

Com a contabilidade digital, busca-se além de economia, mais qualidade e obviamente acesso para todos, desde uma pessoa especial, mães e pais de família, que não têm tempo de ir a escritórios tradicionais. Com mais informação e acesso ao empreendedorismo começa a acontecer e as boas ideias, às vezes perdidas ganham oportunidade para prosperar.

O produto em discussão, Contágora, tem como objetivo atender empreendedores que desejam iniciar seu próprio negócio na cidade de Manhuaçu, Minas Gerais, e regiões adjacentes, por meio da disponibilização de serviços online de contabilidade, podendo atender a todo o estado de Minas Gerais, de acordo com o crescimento da demanda.

Trata-se de um modelo de negócio, criado nos moldes de startup, repetível e escalável, que utiliza ferramentas disponíveis no mercado e permite atender a pessoas físicas, empreendedores, pequenos e médios empresários da cidade de Manhuaçu. 
O produto foi elaborado a partir da "articulação" de um sistema de processamento de informações contábeis interno chamado Domínio Sistemas e o aplicativo ONVIO, ambos da Thomson Reuters, que é uma Plataforma de Gestão Financeira e Fiscal, conhecida como Omie Sistemas; plataformas de redes sociais tais como Instagram, Whatsapp, Linkedin e Facebook, além de um site na WEB para maior alcance. O Produto foi registrado na cidade de Manhuaçu, estado de Minas Gerais, em razão de legislação estadual, para, num segundo momento, expandir para todo o estado e por fim em todo território nacional.

Para entender o funcionamento do produto, parte-se, a título de demonstração de uma situação hipotética, os passos que o cliente/empreendedor interessado deve dar:

Primeiro passo: o cliente/empreendedor tem a ideia do negócio, com isso, como é feito por quase $99 \%$ da população, este acessa a internet em busca de informações sobre sua ideia e descobre existir um escritório de contabilidade digital pronto pra the atender, ele terá acesso a rede sociais do negócio, Instagram, Facebook, Linkedin, Web, WhatsApp.

Segundo passo: consultores especializados entram em contato com o cliente, esclarecendo suas dúvidas, demonstrando as melhores alternativas, instruindo sobre o negócio e sobre as ferramentas que serão necessárias para iniciar o projeto, além de iniciar o plano de negócios com o cliente, este atendimento é feito via Skype, WhatsApp, Instagram, Messenger, ou AnyDesk.

Terceiro passo: faz-se uma assinatura do Contrato de Prestação de Serviços Contábeis Digitais, em que o cliente terá a possibilidade de pagar por meio de plataformas financeiras digitais, como pagseguro, picpay, ou transferências bancárias, NuConta, Banco Inter. Após, será feita uma reunião de alinhamento, a partir daí se dá início ao projeto de empreendedorismo.

Quarto passo: o cliente começa a utilizar as ferramentas online disponibilizadas pelo escritório, para emissão de notas fiscais, boletos e para fazer a gestão financeira de seu negócio, tais como Contaazul Gestão, Omie ou OnBalance, que são exemplos de plataforma disponíveis no mercado.

Quinto passo: O time de especialistas e contadores, recebem as informações, processam, cumprem as exigências legais e fiscais e as devolvem ao cliente por meio de gráficos explicativos, conhecidos como DashBoards, ou seja, 
painéis em português, utilizando também de uma plataforma especifica como ONVIO, da Thomson Reuters, ou outra novas que forem surgindo no mercado.

Sexto passo: Com as informações disponibilizadas pela Contabilidade Digital o empreendedor é capaz de acompanhar o sucesso de seu negócio, fazendo ajustes necessários ao sucesso de seu trabalho, tudo de maneira simples e integrada, facilitando sua rotina diária.

Resumidamente, o modelo de negócio seguirá os passos acima, para que as atividades do escritório da startup tenham um padrão único de qualidade, a fim de garantir a mais completa análise por porte da contabilidade e do cliente.

No período de observação, identificou-se que o contato realizado com os cliente se dá principalmente por WhatsApp, telefone e e-mails, não havendo em nenhuma destas ferramentas controle sobre os atendimentos realizados ou até mesmo sobre a demanda da empresa, assim para encontrar soluções digitais para isso foi necessário buscar alternativas que aumentassem a visualização da empresa e ao mesmo tempo fosse ao encontro dos objetivo do estudo em criar uma Startup de contabilidade digital.

Para criação e funcionamento da startup Contágora buscou-se corrigir tudo que foi observado como pontos falhos no escritório tradicional de contabilidade, como a ausência de controle de tarefas e e-mails, ausência de plataforma para conversas com empreendedores e clientes, falta de um site responsivo, ausência de redes sociais e de gestão de marketing, entre outros problemas. De modo que a Contágora surge da experiência e da observação e da utilização de ferramentas disponíveis no mercado tecnológico. Abaixo apresenta-se algumas soluções buscadas para que o empreendimento seja inovador e eficiente.

\subsection{Controle de tarefas e e-mails}

Para controle de e-mails enviados pela contabilidade, principalmente documentos importantes, a ferramenta encontrada no mercado que vai atender a outras demandas do produto foi a ferramenta Gestta, escolhida por ser a mais utilizada por profissionais da área de contabilidade e principalmente aqueles que almejam a contabilidade digital.

Tal ferramenta consiste em uma plataforma de gestão de tarefas, criada para atender a contadores e escritórios de contabilidade, com um mercado de mais 
de 400 empresas contábeis atendidas, conforme informações do site da empresa, além de possuir diferenciais como: cobrança automática de documentos, baixa automática de tarefas e obrigações e emissão de relatórios de desempenho e performance.

Esta ferramenta permite além de tudo, o trabalho em home office visto que com um controle maior das tarefas executadas por colaboradores, mais fácil de ter profissionais trabalhando no conforto de suas próprias casas e assim contribuir com a redução de gás carbono na atmosfera. O Dashboard da ferramenta auxilia no processo de gestão das atividades executadas pelo escritório, que destaca pontos de atenção para as atividades do escritório, tarefas de hoje e tarefas a serem executadas dentro do mês, além daquelas que podem gerar multas para o cliente, isso permite uma melhorar análise da execução de cada atividade pelos colaboradores.

Também é possível o controle de envio de e-mails para clientes, uma vez que esta ferramenta permite saber se o cliente recebeu ou não e caso responda cai dentro do controle da atividade executada. $\mathrm{O}$ trabalho em home office será gerido pela produtividade de cada trabalhador, com o cumprimento de tarefas especificas, como geração e envio de impostos, declarações mensais, demonstrações financeiras e demais documentos necessários a gestão do negócio.

\subsection{Plataformas de conversas com cliente}

O uso do WhatsApp tem se tornado essencial para qualquer negócio, conforme publicado pela revista Exame o aplicativo de mensagens cresceu até $76 \%$ por conta do Coronavírus, e foi o que registrou o maior crescimento no ano de 2020, acompanhado do TikTok (AGRELA, 2020). E tem atingido cada vez mais pessoas que antes não eram favoráveis as redes sociais. Foi pensando nesse alcance que foi criada a conta de WhatsApp, onde o cliente pode falar diretamente com a empresa.

Além da ferramenta, o uso de aplicativo tem se destacado, visto que com o período de quarentena devido à COVID 19, muitas empresas investiram na ferramenta com o foco de aproximar seus clientes e atendê-los da melhora forma. Com base nisso, a empresa Domínio Sistemas criou o Onvio, que permite ao cliente fazer diversas solicitações ao escritório de contabilidade, além de ter acesso a todos os documentos necessários à sua gestão. 
O acesso ao aplicativo é feito mediante a disponibilização de uma senha pelo escritório de contabilidade, e este pode ser feito também utilizando navegadores web. Além disso, dentro do próprio site existe a funcionalidade liberada pela plataforma WiX que permite ao interessado entrar em contato direto com os consultores da Contágora.

A criação do site atende uma necessidade da maioria das empresas de tecnologia, pois visa dar um caminho ao cliente interessado em encontrar ferramentas que atendam às suas necessidades, ao observar o objeto de estudo deste trabalho constatou-se que o mesmo não mantinha uma página atualizada na web, o que dificultava muito ao acesso de pessoas que não eram oriundas de uma indicação.

\subsection{Marketing contábil}

O marketing digital tem se tornado uma importante ferramenta para divulgação dos serviços prestados por diversas empresas, principalmente em tempo de pandemia Covid 19, que resultou num aceleramento da inovação tecnológica por parte das empresas.

Com base nisso, fica evidente que estratégias de marketing muito bem preparadas, são capazes de proporcionar, conforme um processo de aprendizado contínuo e de interação entre cliente e mercado, além de conseguir transmitir uma comunicação mais eficiente sobre uma empresa e seus produtos e serviços, além de evidenciar valores que hoje estão contidos internamente em cada escritório do Brasil (OKADA; SOUZA, 2011).

No processo de observação, identificou-se que o escritório objeto de estudo ainda não mantinha perfis nas redes sociais, e que a Startup digital necessariamente deveria cria-las, porque são espaços também de marketing digital, uma vez que hoje Instagram, Facebook e Linkedin são redes comerciais também.

E por fim, como já mencionado anteriormente o uso do site da Contagoraon para disponibilização na web. É importante destacar o uso do termo "on" ao final, pois já existe domínio registrado de uma empresa Contagora, assim foi necessário anexar uma diferenciação.

\subsection{Gestão do cliente}


Existe uma grande necessidade por parte das empresas, de manter seu gerenciamento em dia, entretanto muitos empresários encontram dificuldades para realizar este processo ou até mesmo fazê-lo de maneira correta. Conforme Frezatti, Aguiar e Guerreiro (2006), uma empresa que mantém um bom controle gerencial e financeiro aumenta consideravelmente suas chances de sucesso e de progressão do negócio. Com base nisso e através de observação de dentro do escritório, foi necessário encontrar ferramentas que atendesse ao objetivo do presente estudo em oferecer ao cliente um sistema completo de gestão financeira e fiscal e que o mesmo desse ao contador total liberdade para acompanhar toda movimentação financeira e exportar os dados necessários para isso.

Antes, todavia, de se chegar a ferramenta escolhida, foram necessários testes com outras duas ferramentas, a primeira Contazul, e a segunda OnBalance, porém houve muitas dificuldades de adaptação da ferramenta ao sistema, o que trouxe entraves impossibilitando a continuidade dos testes, entre eles a falta de integração com os municípios atendidos pelo produto, e isso resultou em mudança.

Com base no exposto, através de muita pesquisa e conversas com profissionais da área chegou-se à plataforma Omie, que oferece todas as ferramentas necessárias para uma boa gestão, e concede ao contador a possibilidade de acesso simultâneo juntamente com o cliente.

O mais importante para que o processo de contabilidade digital aconteça da forma mais completa possível é a possibilidade da exportação de todos os dados lançados dentro do sistema para a importação do contador para o seu sistema contábil.

Com essa plataforma, os operadores da Contágora importarão todos os dados do cliente para dentro do sistema contábil de processamento e gerarão todos os informativos necessários que irão disponibilizar ao seu cliente por meio do aplicativo ONVIO, no Portal do Cliente.

\subsection{Sistema contábil de processamento}

Um bom escritório precisa de um bom sistema, para que isso aconteça da melhor forma, foi observado que a empresa objeto de análise já mantinha um sistema, porém existia somente em servidor físico, o que para a criação de Startup Contágora $100 \%$ digital seria um entrave, visto que o produto proporciona o trabalho 
em Home Office neste passo, identificou-se que o mesmo dispunha de ferramentas em nuvem para atendimento.

Além disso, uma vez acessado o sistema, ele permite ao operador, diretamente da sua casa, fazer a importação do arquivo em formato txt e gerar todos os demonstrativos fiscais e gerenciais, além de postá-los aos clientes por meio do Portal do Cliente, o Onvio. Além disso o sistema oferece de madeira remota, todas as ferramentas necessárias para se fazer a contabilidade de uma empresa, isto posto, os arquivos gerados por ele constavam no aplicativo em tempo real, além de permitir interação entre cliente e empresa de contabilidade.

Um dos fundamentos da criação da Startup Contágora é que haja uma interação constante entre contato e cliente. E por meio de observação constatou-se ainda a possibilidade de utilizar-se de inúmeras ferramentas para melhorar esta interação, tal como Trello, Evernote, Pipefy, entre outras disponíveis no mercado na data atual da pesquisa.

E por fim, tem-se o processo de importação de dados feitos pelos operadores, sem dificuldades para execução, uma vez que o sistema é previamente configurado para que tudo ocorra de mais simples possível, e que os operadores possam se dedicar à consultoria preventiva aos clientes.

Atualmente no mercado existem empresas que prometem a contabilidade digital, porém o que diferencia este produto dos demais é que muitas dessas empresas utilizam um sistema próprio para isso, o que gera um custo muito mais expressivo devido a investimento em tecnologia da informação. Outros casos são de empresas que apenas adotam a importação de notas fiscais de entrada de forma automática, mas não oferecem uma experiência completa digital ao cliente.

Além disso, existe a proposta do cliente visualizar mensalmente o quanto ele tem contribuído para o não aquecimento global com a economia de papel, redução nos custos de transporte até um escritório de contabilidade e o uso do pagamento de boletos.

Todas estas ferramentas apresentadas juntas formam e ao mesmo tempo une empreendedores e escritório. Com o auxílio de todas elas é possível atender as necessidades específicas de cada um, o que consiste em diferencial importante.

\section{CONSIDERAÇÕES FINAIS}


O presente estudo buscou encontrar soluções no âmbito da contabilidade que atendessem a ideia inicial de criação de uma startup, que pudesse contribuir com empreendedores, pequenos e médios, na cidade de Manhuaçu, Minas Gerais, e regiões adjacentes.

O objetivo do trabalho foi atingido ao verificar que a startup criada buscou melhorar todos os problemas verificados no decorrer da observação do funcionamento de um escritório tradicional. Os pontos mais observados e com maiores gargalos eram na relação/informação entre contador e cliente.

Observou-se que há um desconhecimento por parte dos profissionais da área de Contabilidade sobre as ferramentas existentes no mercado que permitem melhorar os processos internos e de atendimento ao cliente, desde a captação até a geração de informações legais e gerenciais.

Destaca-se a dificuldade de encontrar algumas ferramentas como de gestão integrada entre cliente e contabilidade, visto só ser possível por meio da internet e por cursos hoje oferecidos que auxiliam na tomada de decisão, porém nem todos oferecem exatamente o que prometem. Por conta disso a escolha de uma única ferramenta permitiu explorar mais por sua funcionalidade.

Umas das maiores dificuldades encontradas para execução se deu inicialmente por conta da pandemia, pois com isso impossibilitou visitas pessoais a clientes e também aplicação de instrumentos de pesquisa, de modo que optou-se pela observação do escritório tradicional de uma empresa de Contabilidade para criar uma startup que corrigisse os problemas observados, e, assim, nasceu a Contágora.

A grande vantagem da Contágora é que ela opera com vários sistemas integrados, daí a possibilidade de maior sustentabilidade, já que as ferramentas selecionadas favorecem o contador e pode facilitar o empreendedorismo em diversas áreas.

Diante do exposto, conclui-se que a contabilidade digital é uma evolução necessária ao processo contábil e permite que a informação chegue em tempo hábil a um empreendedor/cliente, de modo que os profissionais contadores trabalhem mais focados no processo de consultoria digital em vez de geração de impostos e atendimento às obrigações com o fisco.

Por fim, é importante destacar a necessidade de estudos futuros focados em 
conteúdo de marketing digital para contadores, visto que com o desenvolvimento deste trabalho se identificou muito desconhecimento do que pode ou ser feito, além de não ser muito discutido entre a categoria.

\section{REFERÊNCIAS}

AGOSTINI, Carla; CARVALHO, Joziane Teresinha. A evolução da contabilidade: seus avanços no Brasil e a harmonização com as normas internacionais. Instituto de Ensino Superior Tancredo de Almeida Neves, [s. I.], v. 1, p. 1-24, 2012.

AGRELA, Lucas. WhatsApp cresce até $76 \%$ por causa do coronavírus: o aplicativo de mensagens cresceu mais em países com grande número de casos da covid-19. Exame, [s. I.], 2020. Disponível em: https://exame.com/tecnologia/whatsapp-cresceate-76-por-causa-do-coronavirus/. Acesso em: 17 nov. 2020.

BIELINSKI, Alba Carneiro. Educação profissional no século XIX - curso comercial do Liceu de Artes e Ofícios: um estudo de caso. Boletim Técnico Do Senac, [s. I.], v. 26, n. 3, p. 1-11, 2000. Disponível em: https://www.bts.senac.br/bts/article/view/824. Acesso em: 25 set. 2011.

FIBONACCI: italian mathematician. Britannica, [s. I.], 2011. Disponível em: https://www.britannica.com/biography/Fibonacci. Acesso em: 17 nov. 2020.

FRANCO, H. Contabilidade geral. 23. ed. São Paulo: Atlas, 1997.

FREZATTI, F., AGUIAR, A. B. de, GUERREIRO, R. Diferenciações entre a contabilidade financeira e a contabilidade gerencial: uma pesquisa empírica a partir de pesquisadores de vários países. In: ENCONTRO DA ANPAD, 30., 2006, Salvador. Anais [...]. Salvador: ANPAD, 2006. p. 1-16. Disponível em: http://www.anpad.org.br/abrir_pdf.php?e=NTgyMg==. Acesso em: 17 nov. 2020.

IUDÍCIBUS, Sérgio de; MARION, José Carlos. Introdução à teoria da contabilidade: para o nível de graduação. 4. ed. São Paulo: Atlas, 2007.

LIMA, Ariovaldo Alves. Contabilidade básica. 3. ed. São Paulo: Atlas, 2006.

MERCADO da tecnologia cresce $118 \%$ em dez anos no Brasil: empresômetro aponta que serviços de tecnologia tiveram alto crescimento no País.

Computerworld, [s. I.], 2019. Disponível em:

https://computerworld.com.br/negocios/mercado-da-tecnologia-cresce-118-em-dezanos-no-brasil/. Acesso em: 3 mar. 2021.

NIYAMA, Jorge Katsumi. Contabilidade internacional. 2. ed. São Paulo: Atlas, 2009.

OKADA, Sionara Loco; SOUZA, Eliane Moreira Sá de. Estratégias de marketing digital na era da busca. Revista Brasileira de Marketing, [s. I.], v. 10, n. 1, p. 46-72, 
2011.

ONU. Os objetivos do desenvolvimento sustentável no Brasil. Nações Unidas Brasil, [s. l.], 2020. Disponível em: https://brasil.un.org/ptbr/sdgs\#: :text=e\%20no\%20mundo.,Os\%20Objetivos\%20de\%20Desenvolvimento\%20Sustent\%C3\%A1vel\%20no\%20Br asil,de\%20paz\%20e\%20de\%20prosperidade. Acesso em: 17 nov. 2020.

PALHARES, Antonio; RODRIGUES, Laercio de Castro. Introdução à contabilidade. São Paulo: Scipione, 1990.

REIS, Aline de Jesus; DA SILVA, Selma Leal. A história da contabilidade no Brasil. Seminário Estudantil de Produção Acadêmica, [s. I.], v. 11, n. 1, p. 1-13, 2007.

SANTOS, Bruno P. et al. Internet das coisas: da teoria à prática. In: SIMPÓSIO BRASILEIRO DE REDES DE COMPUTADORES E SISTEMAS DISTRIBUIDOS, 34., 2016, Salvador. Anais [...]. Salvador: UFBA, 2016. p. 1-50.

SEBOLD, M. et al. Evolução da contabilidade brasileira: do governo eletrônico ao sistema público de escrituração digital - SPED. Enfoque: Reflexão Contábil, [s. I.], v. 31, n. 2, p. 23-32, 2012. 